\title{
Patient Safety in Primary Care: Conceptual Meanings to the Health Care Team and Patients
}

\author{
Alden Yuanbong Lai, PhD, Christina T. Yuan, PhD, Jill A. Marsteller, PhD, \\ Susan M. Hannum, PhD, Elyse C. Lasser, MS, JaAlab-Ai Heughan, MS, \\ Tyler Oberlander, BA, Zackary D. Berger, MD, Ayse P. Gurses, PhD, \\ Hadi Kharrazi, MD, PhD, Samantha I. Pitts, MD, Sarah H. Scholle, PhD, and \\ Sydney M. Dy, MD
}

Introduction: Patient safety in primary care is an emerging priority, and experts have highlighted medications, diagnoses, transitions, referrals, and testing as key safety domains. This study aimed to (1) describe how frontline clinicians, administrators, and staff conceptualize patient safety in primary care; and (2) compare and contrast these conceptual meanings from the patient's perspective.

Methods: We conducted interviews with 101 frontline clinicians, administrators and staff, and focus groups with 65 adult patients at 10 patient-centered medical homes. We used thematic analysis to approach coding.

Results: Findings indicate that frontline personnel conceptualized patient safety more in terms of work functions, which reflect the grouping of tasks or responsibilities to guide how care is being delivered. Frontline personnel and patients conceptualized patient safety in largely consistent ways.

Discussion: Function-based conceptualizations of patient safety in primary care may better reflect frontline personnel and patients' experiences than domain-based conceptualizations, which are favored by experts. ( J Am Board Fam Med 2020;33:754-764.)

Keywords: Administrative Personnel, Focus Groups, Patient Safety, Patient-Centered Care, Practice-Based Research, Primary Health Care, Qualitative Research, Referral and Consultation

\section{Introduction}

Improving patient safety can not only avert preventable deaths but also reduce morbidity, costs, and distress for patients as well as health care professionals. ${ }^{1,2}$ Since the Institute of Medicine published "To Err is Human", patient safety efforts have proliferated; although, they have focused more on the

This article was externally peer reviewed.

Submitted 28 January 2020; revised 14 April 2020; accepted 14 April 2020.

From the Department of Public Health Policy and Management, New York University School of Global Public Health, New York City (AYL); Department of Health Policy and Management, Johns Hopkins Bloomberg School of Public Health, Baltimore (CTY, JAM, ECL, J-AH, APG, HK, SMD); Armstrong Institute for Patient Safety and Quality, Johns Hopkins School of Medicine, Baltimore (CTY, JAM, APG, SIP, SMD); Department of Anesthesiology and Critical Care Medicine, Johns Hopkins School of Medicine, Baltimore (CTY, JAM, APG); Department of Health, Behavior and Society, Johns Hopkins Bloomberg School of Public Health, Baltimore (SMH, ZDB); National Committee for Quality Assurance, Washington DC (TO, SHS); Division of General Internal Medicine, Johns Hopkins School of Medicine, inpatient setting than its ambulatory counterpart. ${ }^{4}$ Yet, 23 times more people receive services in primary care than in hospitals in the United States yearly. ${ }^{5,6}$ Expert consensus highlights medications, diagnosis, transitions, referrals, and testing as key domains in primary care. ${ }^{4,7,8}$ Although some of these domains overlap with the inpatient setting, primary care faces additional challenges that may create safety concerns: (1) there is a heavier reliance on patients for disease management; (2) clinical

Baltimore (ZDB, SIP, SMD); Division of Health Sciences Informatics, Johns Hopkins School of Medicine, Baltimore (APG, HK).

Funding: This work was supported by the Agency for Healthcare Research and Quality (grant number R01HS024859).

Conflict of interest: Tyler Oberlander and Sarah $\mathrm{H}$. Scholle are employed by the National Committee for Quality Assurance, which recognizes patient-centered medical homes. All other authors declare no conflict of interest.

Corresponding author: Alden Yuanhong Lai, PhD, 715 Broadway, 10th Floor, \#1000A New York, NY 10003 (E-mail: aldenlai@nyu.edu). 
encounters are typically short and episodic; (3) fragmentation exists among electronic health record systems; and (4) practices are more sensitive to changes in size, financing, leadership, and culture. ${ }^{4}$ These characteristics warrant the need to explore patient safety in primary care, especially given our increasing need for health services and limited knowledge of safety issues in this setting. ${ }^{9-11}$

Previous research on safety in primary care has examined the epidemiology of medication errors, ${ }^{12,13}$ error reporting tools, ${ }^{14}$ and perceptions of safety culture. $^{15,16}$ A distinct way of contributing to this increasingly important area is to investigate what patient safety in primary care means to those on the frontlines delivering care as well as the patients receiving it. This investigation is useful because, first, clarifying conceptual meanings is often a foundational step for addressing burgeoning topics in the health sciences. ${ }^{17-19}$ Second, identifying the meanings generated can help us understand, predict, and improve the actions taken by frontline personnel and patients. ${ }^{20-22}$ Third, patient safety research in primary care has tended to focus on the perspectives of either professionals or patients, without efforts to examine them simultaneously. ${ }^{23-25}$ By systematically eliciting the meanings from a representation of not only professionals but also administrators, staff, and patients, we can include a wider range of conceptualizations and identify elements that are important to, and how they are different across, stakeholder groups. Such findings can generate potential research directions for scholars as well as preliminary ways for managers to think about the design, implementation, and evaluation of patient safety interventions in primary care.

Our primary research aim was to elucidate the conceptual meanings of patient safety among frontline clinicians, administrators, staff, and patients in the primary care setting. Second, we compared and contrasted the meanings to clinicians, administrators, and staff with those to patients to ascertain the degree of alignment.

\section{Methods}

\section{Study Design and Sample}

We conducted a qualitative study that involved interviews with 101 frontline clinicians, administrators, and staff (hereafter, "personnel") and 12 focus groups with a total of 65 patients. We collected data in 10 patient-centered medical homes (PCMHs) that had achieved level 3 status in the National Committee for Quality Assurance (NCQA) PCMH recognition program. $^{26}$ At the time of study, level 3 PCMHs were practices that NCQA determined as performing at the highest level (there were 3 levels in total) based on 6 aspects of primary care delivery, including patient access, team-based care, care management and support, care coordination, quality improvement, and population health management. ${ }^{27}$ The 10 PCMHs included in our sample were located in 4 US states of Colorado, Maryland, North Carolina, and Pennsylvania and had a median of 3.5 years as a level 3 PCMH before the point of data collection. As an initial step to understand patient safety in primary care, this study focused on level 3 PCMHs because they could potentially show what patient safety in high-performance primary care settings entails. ${ }^{28}$ We first adopted a purposive sampling frame to maximize the types of PCMH practices (ie, ownership and geographical types) for our study because such variation could theoretically generate a dataset that was as rich as possible for the purpose of qualitative analysis. We then used volunteer sampling to recruit practices within each frame. This was because our study involved interviews with a majority of each PCMH's personnel and some of their patients, which necessitated certain changes to their daily operations and therefore the need for them to "volunteer" as a study participant. Patients were eligible to participate if they were over the age of 18 , had a chronic medical condition, and visited the PCMH more than once a year. Each PCMH communicated to their eligible patients about the study through flyers, letters, and e-mails, and those who were interested to participate were requested to contact our study team directly. The Institutional Review Board at the Johns Hopkins Bloomberg School of Public Health (no. 7497) approved this study. All participants provided written informed consent.

\section{Data Collection}

We worked in teams of 3 to 4 members to collect data at the $10 \mathrm{PCMH}$ practices and posed the broad question "What does safe medical care mean to you?" to all participants. We allowed the participants to elaborate as much as possible, including the use of related terms (eg, safe care, patient safety, and keeping patients safe) to elicit further descriptions. ${ }^{29} \mathrm{We}$ interviewed personnel individually and conducted focus groups for patients. Personnel did not share their perspectives in the presence of patients. Patients, on the other hand, only shared their perspectives in the 
Figure 1. Schematic representation of the team-based process used for thematic analysis.

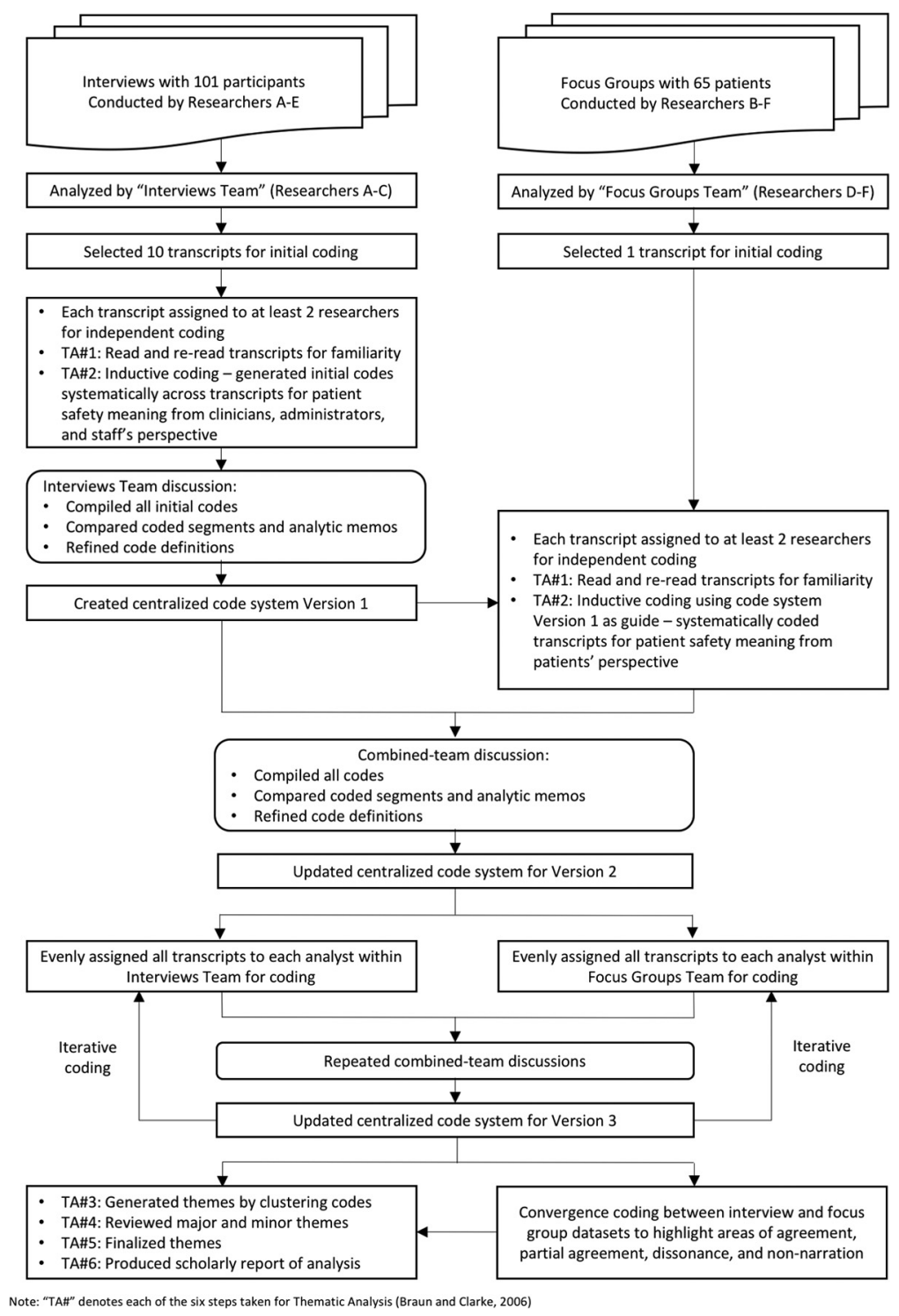

presence of other patients in the focus group. All interviews and focus groups were audio-recorded and professionally transcribed. We visited each site once over a 2-day period between May 2017 and May 2018. This study was part of a parent study that sought to investigate the implementation of the PCMH model and how it related to patient safety. The data reported here were the result of a separate analysis of the responses to the aforementioned open question, which was used at the beginning of all interviews and focus groups in the parent study. We wanted to capture, in the broadest sense, how the participants conceptualized patient safety, and thus limited the current analysis to the responses to this question. The responses typically took the first 5 to 10 minutes. The interviews lasted approximately 30 to 90 minutes in their entirety and 60 minutes for the focus groups.

\section{Data Analysis}

We used a team-based coding process and conducted thematic analysis in 6 phases. ${ }^{30,31} \mathrm{We}$ used a $10 \%$ subsample from each data source to develop a team-based codebook. Because we interviewed 101 personnel, we first randomly selected 10 personnel interview transcripts, which were independently and inductively coded by 3 analysts to derive initial 
codes. The analysts then compared their coded segments for each transcript, refined the code definitions, and created a centralized codebook. During this process, the focus was on discussing disagreements in codes, ways of coding, and alternative explanations for codes as opposed to calculating intercoder agreement. ${ }^{32,33}$ Afterward, another 3 analysts used this newly created centralized codebook to guide the coding of a $10 \%$ subsample of the focus group data, which translated to 1 patient focus group transcript. All 6 analysts then reconvened to compare their codes and coding, revised the centralized codebook, and used it to formally analyze all data. During this process, there was a third update to the centralized codebook as both teams conducted analysis iteratively. When all coding was completed, we began to search for themes by collating codes and reviewed major and minor themes for reporting. ${ }^{30}$ See Figure 1 for a schematic of the analytic steps.

To compare and contrast the perspectives of personnel, and those of patients, 1 analyst conducted a convergence assessment to ascertain areas of agreement, partial agreement, dissonance, and nonnarration. $^{34,35}$ Agreement refers to a direct overlap between the themes and descriptions given from both perspectives; partial agreement refers to a general overlap, but with deviating nuances to be accounted for; dissonance refers to a direct disagreement; and nonnarration refers to a lack of expression of a set of themes or descriptions by 1 stakeholder group compared with the other. We used MAXQDA 12 software for data analysis. ${ }^{36}$ All researchers involved in data analysis were also involved in data collection. The research team comprised health care scholars and primary care physicians with a diversity of backgrounds, including patient safety, patient-centered outcomes research, health services research, implementation science, organizational behavior, gerontology, health information technology, and human factors engineering. To maintain reflexivity, we created and used team memos throughout the data analysis process ${ }^{37}$ and held multiple rounds of team discussions that led to the iterative refinement of the codebook and coding process.

\section{Results}

The interview participants comprised 37 administrators, 25 physicians, 11 medical assistants, 9 care coordinators/navigators, 8 nurses, and 11 others (dental staff, pharmacists, social workers, and
Table 1. Demographic Information of 101 Frontline Clinicians, Administrators, and Staff*

\begin{tabular}{lc}
\hline Characteristic & Values \\
\hline Profession $^{\dagger}, \mathrm{n}$ (\% of sample) & \\
Administration or management & $37(36.6)$ \\
Care coordinator/navigator & $9(8.9)$ \\
Medical assistant & $11(10.9)$ \\
Nurse & $8(7.9)$ \\
Physician & $25(24.8)$ \\
Other (dental staff, pharmacist, & $11(10.9)$ \\
physician assistant, and social worker) & \\
Sex, n (\% of sample) & $78(77)$ \\
Female & $23(23)$ \\
Male & 4 years (1 month - \\
Median number of years working at & 29 years) \\
practice (range)
\end{tabular}

*Participants were from 10 patient-centered medical homes who took part in individual interviews conducted between May 2017 and May 2018 on patient safety in primary care.

${ }^{\dagger}$ Respondents who held more than one role (ie, administration and clinical) were classified by their clinical profession in this table.

physician assistants) who had worked for a mean of 6 years in their practice. Most of the patient focus group participants were female $(53.8 \%)$, white (84.6\%), between the ages of 46 to $65(33.8 \%)$, and had a college degree/completed some college (47.7\%). The PCMH practices included in our sample fully reflected the purposive sampling frame we adopted: 5 of the practices were hospital/health system owned, 4 were independent clinician owned, and 1 was a federally qualified health center. Six of the practices were located in suburban areas, 3 were in rural areas, and 1 was in an urban area. See Tables 1 and 2 for other participant characteristics.

We identified 5 main themes in the form of "work functions" related to how personnel and patients conceptualized the meaning of patient safety in primary care. We defined work functions as the tasks or perceived responsibilities that are grouped in particular ways to guide how work is being done. Furthermore, the theme names were grounded in the participants' own expressions of their conceptualizations. They include (1) not causing harm, (2) viewing patients' needs holistically, (3) providing appropriate and timely care, (4) ensuring physical safety and informational security, and (5) communicating attentively. The second theme contains 1 subtheme: (2a) considering social determinants of health (SDOH); and the third theme contains 2 subthemes: (3a) coordinating care and 
Table 2. Demographic Information of 65 Patients*

\begin{tabular}{lc}
\hline Variable & $\mathrm{n}(\%$ of sample) \\
\hline Age range & \\
$18-45$ & $10(15.4)$ \\
$46-65$ & $22(33.8)$ \\
$66-75$ & $20(30.8)$ \\
$>75$ & $12(18.5)$ \\
Did not wish to answer & $1(1.5)$ \\
Sex & \\
Female & $35(53.8)$ \\
Male & $26(40)$ \\
Did not wish to answer & $4(6.2)$ \\
Race & \\
Asian & $1(1.5)$ \\
Black/African American & $3(4.6)$ \\
Native American & $1(1.5)$ \\
White & $55(84.6)$ \\
Did not wish to answer & $5(7.7)$ \\
Education & \\
College degree/some college & $31(47.7)$ \\
Degree after college & $8(12.3)$ \\
High school graduate/some high school & $25(38.5)$ \\
Did not wish to answer & $1(1.5)$ \\
\hline
\end{tabular}

*From 10 patient-centered medical homes who participated in focus groups conducted between May 2017 and May 2018 on patient safety in primary care.

(3b) shared decision-making. Overall, personnel and patients conceptualized patient safety in primary care in largely consistent ways, with some areas of divergence that are described below.

We detail the results in the following order. First, we elaborate 4 of the 5 themes that emerged from the inductive coding of personnel interview data. We present these themes in conjunction with the convergence assessment against patient data to highlight areas of agreement, partial agreement, dissonance, or nonnarration. Second, we present results on the final theme that emerged from the inductive coding of the patient focus group data, which was not highlighted in the personnel interviews. See Appendix for a tabular presentation of the results.

\section{Elaboration of Themes and Degree of Convergence}

\section{Patient safety as not causing harm}

Personnel conceptualized patient safety as not causing harm to patients when providing care, with emphasis on the effects of medications and procedures and how they could potentially impact patients:

"I take that Hippocratic Oath of 'do no harm' very seriously. Every kind of prescription I give, every decision I'm going to make, I always think, am I doing more harm than good, so that's sort of my mantra." -physician, identifier [ID] 55, site 6

There was agreement on this theme with how patients conceptualized safety. Patients recognized the importance of having their health care providers pay attention to their medications in particular, due to similar concerns about potential adverse effects.

"They [the practice] always keep up with your medicine. That's just very important to me. Especially being diabetic. Because some of those medicines just will not, they just don't agree with me. And it's scary when your blood sugar drops and you're just in a pickle." -patient $\mathrm{C}$, site 9

However, as personnel highlighted nonmaleficence as part of patient safety, a consideration surfaced when they also acknowledged that medical treatments will always pose some risk of harm to patients. To address this, they described efforts to (1) select medical interventions that balanced minimal risks with maximal benefits and (2) ensure that medical procedures were error free:

" $[\mathrm{H}] \mathrm{arm}$ is unavoidable. The nature of the way we practice medicine...there is no drug that comes without adverse effects. I tell my patients, every time we start with a new med, there is no drug that you will take that will not have some complications. There is a sort of unavoidable nature, but I think our job is to pay attention and to try to minimize the complications to the extent that they are minimizable." -physician, ID 82, site 8

"Safe medical care is doing our due diligence...eliminating opportunities for error through systematic ways and accounting for the fact that we know that we don't know everything, so to the best knowledge, kind of giving 110 percent each time to make sure that there are no opportunities for errors, but to also be able to adapt to those opportunities when they come." -pharmacist, ID 70 , site 7

Patient safety as viewing patients' needs bolistically

Personnel viewed patient safety as considering patient needs from various aspects, which included primary and specialist care needs, mental health needs, dental health needs, and the needs that patients have when they are at home or traveling. A physician detailed this view when assessing risks to patients' health to identify those that were relevant to safety:

"Patient safety to me, runs a gamut of a whole spectrum of things. It begins in the entire realm 
of medical care starting in regards to the patient at their home and evaluating that through the entire continuum of medical care, whether it's here at the office, our urgent care centers, our hospital, or any other medical facility. And then, try to evaluate the patient in regards to where are those risks? To the patient's wellbeing? To their health? To their chronic medical illnesses, etcetera. It exists in multiple different areas of the patient's life." -physician, ID 38, site 4

Patients showed agreement with this view of patient safety. They emphasized the need for health care providers to "look at the whole picture and know the right questions to ask" (-patient A, site 2). A patient positively recalled her physician delving into the life events that might have contributed to hypertension instead of suggesting a drug intervention immediately:

"I think what I've found is that my doctor looks at all of me. Patient A has high blood pressure, oh she's anxious. No. Looking at the whole big picture...what's going on in life? What has made you anxious? So not just pinpointing, oh here's a medication for that. [The doctor is] looking at all of me and I like that. I like that feeling." -patient A, site 1

Considering SDOH. In keeping with the holistic needs of each patient, personnel highlighted the importance of patients' SDOH and access to health and social services. Personnel reflected these concerns as well as efforts to address them:

"Social determinants when they [patients] come in, thinking about those types of things, like, do they have insurance? Do they have a job? Do they have ways of paying for medications? Especially chronic diseases. . . because sometimes they'll come in and they don't have the money to pay for medications and that's not safe for them if they can't take their medicine, so we try to help them as best as we can." -practice manager, ID 82, site 9

Patients, however, did not highlight their personal and socioeconomic situations as part of safety. This subtheme was therefore classified as nonnarrated among patients.

\section{Patient safety as providing appropriate and timely care}

Personnel also emphasized delivering care that was "right," elaborated in terms of appropriateness and timeliness. They conceptualized this in terms of treatment plans and time in which treatment was provided:

"First, do no harm. But, in a broader sense, it is the right care for the right patient at the right time. It means understanding the patient, their situation in a timely way, which would involve recognition of issues in a timely way, and then direction into the right treatment pathways." physician, ID 65 , site 7

From the patient perspective, there was agreement for this theme. There was an expectation of having their clinical conditions addressed with appropriateness and timeliness when receiving primary health care:

"When you come here and see a doctor or PA [physician assistant] for medical advice and care, it's care that's going to take care of you. And in fact, what you're coming in with is going to be dealt with. If they can't cure it, at least they can tell you what it is and maybe start you on a program to handle that. It doesn't get worse and they don't misdiagnose. I'd say those are the two things that would make me wonder if it's safe." - patient A, site 3

Coordinating care. A subtheme emerged when personnel specifically highlighted the role of care coordination for patients as a key aspect of safety. They described the responsibilities of facilitating, from the beginning to end, and in a timely way, the required follow-up tests, procedures, and specialist referrals for patients:

"If their safety is they need a CAT [computerized axial tomography] scan, we have to make sure it's going to get done and get it done in a timely manner and make sure that if anything has to happen after that, if they need to see a surgeon or whatever, that's safety because we're seeing the patient from beginning to end and make sure that, again, that loop is completed...And the other thing, too, is following through with referrals, appointments to a specialist and tests, and things that the doctors order at the time of the visit. So, we do a loop with ordering it, scheduling it, following through, and we get the report." -administrator, ID 39, site 4

This subtheme was however only in partial agreement against patients' conceptualization of safety. Personnel focused on the activities they were performing for care coordination, whereas patients instead focused on the trust they placed in their own primary care providers and that their medical needs would be met appropriately and timely as well when being referred to other providers. Patients therefore affiliated an element of trust with patient safety in the care coordination process:

"You rely more on your primary care physician to direct you to the specialties and I think hopefully you have trust in them enough that they are 
directing you to the proper specialty because I think that concerns me as far as safety because I don't know who's out there, so I have to rely on her to tell me now okay, we're going to set up an appointment for you with Dr. so-and-so to look at whatever. So, how are we to know with the professional we're now going to. We're leaving our primary care physician, who we liked very much, is directing us to the right specialty." patient $\mathrm{E}$, site 4

Shared decision-making. Personnel also perceived patient safety as the inclusion of the patient as a partner when deciding on medical treatments and managing their health:

"[Patient safety is] care where we get the best outcome for the patient...get the patient involved...I've always had my philosophy that the patient needs to be involved. And my role is a consultant and teaching the patient as much as possible as to what's going on. Patient safety is that the patient is aware of it, knows why we're doing it, is on board with doing whatever the intervention is and complies with it and hopefully gets the good results." -physician, ID 17, site 2

There was agreement on this notion of shared decision-making from the patient point of view. Patients described that safe care was when they were able to comprehend the diagnosis, proposed treatment, and potential risks for their condition. These entailed being an active participant of the medical decision making process:

"Ensuring that the patient understands what's going on, why you're doing it, what the risks are, what the complications may be, and involving the patient in involving the patient in their own treatment so that they understand the importance of what has to be done and why they should do it and to me, that's safety. That's important safe medical care." -patient C, site 2

\section{Patient safety as ensuring physical safety and informational security}

The concept of patient safety also extended to the infrastructure of the practice environment. Personnel emphasized patient safety in this realm in 2 ways, which were in agreement with patients' views. The first was ensuring that patients, especially older adults, were free from fall risks during visits. Safety was about the ease with which patients can physically navigate around the clinic and that equipment was available for use to mitigate fall risks.

"So safe medical care means to me that when the patient comes in, they can safely get to the chair, they can safely room, go to the bathroom by themselves. . .their stability and their balance and everything are intact where they're not falling. Very simple. Well, there are bars in the bathroom for the patient to make sure that they can sit properly if they are handicapped and there's no steps. There's a ramp and there's the doors that open automatically, which we use. Probably what I would assess here at the practice being patient safety is that we have the bars and we have the equipment." -medical assistant, ID 58, site 6

Patients similarly echoed considerations for the ease of arriving at the clinic and physical safety:

"I'm ambulatory, but I do walk with a cane. So, to me it starts before I get into the office. Is there snow removal, ice, handicap parking, can I even make it to the door...I've been to specialist's office in the winter time and had to just say no. I'm not even going to attempt it. Snow, ice, steps, no handicap [parking]." -patient $\mathrm{C}$, site 6

The second component was the emphasis on protecting confidential patient information from unintended use. Personnel highlighted the responsibility to protect patient information in accordance to existing legislation on data security ${ }^{38}$. Patients similarly highlighted concerns for identity theft and secure handling of their information.

"Patients feeling like their information is safe and that they feel like their HIPAA [Health Insurance Portability and Accountability Act] is not being violated. I think sometimes the office is a bit like, you're seeing other patients, your information is kind of there...I think that that's an important part of patient safety is making sure their health information is safe." - physician, ID 87 , site 10 "In light of everything that's going on in the world today with identity theft, I'm concerned with measures that are taken, that our records will be secure. I'm also concerned that when new applicants come to the clinic to work at the clinic, from doctors all the way down to the person answering the phone...that these people are also reliable and not people that would take our information and somehow use it." -patient B, site 4

\section{Patient safety as communicating attentively}

Attentive communication emerged as a theme from the patient focus group data, which was nonnarrated when contrasted with the personnel interview data. Patients felt safe when they perceived that their primary care provider had actively listened and considered the information provided in the course of the clinical encounter. Communication was also integral 
in the subthemes (3a) coordinating care and (3b) shared decision-making, but we distinguished this theme because of the interpersonal component of active listening and the willingness by personnel to engage in conversations and act on the information being exchanged. Collectively, they underlay a patient-provider relationship that signaled safety to patients:

"We all have different little medical concerns and you can just ask him [the physician] a question and you get an answer so quickly...so I feel safe in the fact that he's actually listening to me and actually hearing everything I have to say...you think you have this and it's like 'no, you don't have that you have this,' and it's so much simpler. You're not so worried because we do go on the Internet and we do read things and you're like oh my God, I have this and I'm going to die. So, I feel safe that he listens to me and that I'm going to get the right results." -patient $\mathrm{B}$, site 5

\section{Discussion}

We identified 5 work functions on how frontline clinicians, administrators, staff, and patients conceptualize the meaning of patient safety in primary care. The conceptual meanings of patient safety to personnel working in primary care are largely consistent with those of patients with some divergence: coordinating care, where personnel were focused on the tasks involved, but patients were focused on the relationships instead; considering social determinants of health, which was nonnarrated in patients' conceptualization of safety; and communicating attentively, which was nonnarrated in personnel's conceptualization of safety. By systematically investigating how frontline clinicians, administrators, staff, and patients conceptualize patient safety in primary care, this study responds to calls to include the patient perspective in patient safety research ${ }^{39}$ and seeks to provide some foundational context that may help advance future patient safety efforts in primary care. ${ }^{40}$

Experts have highlighted the importance of 5 safety domains in primary care: medications, diagnosis, care transitions, referrals, and testing. ${ }^{4,7}$ However, our findings indicate that (1) functionbased conceptualizations of patient safety better reflect the experiences of personnel than domainbased conceptualizations; (2) informational security, which is not highlighted in the expert view, is also perceived as an element of patient safety in primary care; and (3) conceptualizations of patient safety in primary care have a large overlap with those in quality of care. ${ }^{41}$ Of note, the considerations in both the function-based or domain-based conceptualization are largely consistent. The theme Not Causing Harm had a particular emphasis on medication safety. The theme Providing Appropriate and Timely Care emerged from participants' descriptions around diagnoses, care transitions, referrals, and testing. This study instead demonstrates that personnel conceptualize patient safety more in terms of work functions that traverse these domains. Second, there may be a need to extend the existing foci in primary care safety beyond the clinical domains to include issues related to informational security and confidentiality. ${ }^{25}$ Collectively, these findings can inform how and what to start measuring patient safety performance in primary care, especially when the number of safety indicators specific to primary care remains limited compared with the inpatient measures. ${ }^{42,43}$

The analytic classification of a personnel or patient perspective as nonnarrated does not sufficiently indicate that it is not considered important and/or an element of patient safety to them. This study sought to capture the meanings of patient safety that were most salient to the participants. A lack of narration may therefore be resultant of what participants considered to be associated with patient safety or not, instead of a complete absence of conceptualization. The subtheme considering social determinants of health was classified as nonnarrated in patients' conceptual meaning of patient safety in primary care when juxtaposed with that of personnel. As a concept, SDOH is challenging to understand generally, ${ }^{44}$ which may explain why patients did not articulate particular social factors and their influence on health as a part of patient safety in primary care as much as personnel. An alternative explanation is that patients may not consider $\mathrm{SDOH}$ as a domain of responsibility under their primary care provider. Future research should address how SDOH and patient safety are being considered in the delivery of primary care to gain clarity on this aspect of safety.

As personnel in PCMHs conceptualized care coordination as a part of the meaning behind patient safety in primary care, they adopted a task orientation, in which the focus was to conscientiously complete tasks to ensure that patients' 
care coordination needs were being met. In comparison, patients adopted a relationship orientation to care coordination. Patients placed more weight on the trust in their primary care provider to refer them to other health care professionals that were able to meet their health care needs. From the patient perspective, care coordination activities in the context of patient safety are therefore not limited to their primary care provider(s) but also extend to the external professionals whom they are being referred to. To enhance patients' perceptions of safety, primary care practices can consider emphasizing relevant information (eg, history of referring patients to this particular specialist and feedback from other patients) to foster the trust that underlies patients' construal of safety.

Last, patients conceptualized attentive communication as part of patient safety in primary care. They perceived care as safe when their primary care provider actively listened and considered the information they provided as diagnostic and treatmentrelated decisions were being made. This is also compatible with a function-based conceptualization of patient safety. In particular, patients perceive care delivery to be safer when their primary care providers can demonstrate that they are paying attention to the information being shared by the patient during the clinical visit. Previous research has highlighted the importance of "patient-centered communication" when delivering care, which also increases patient satisfaction. ${ }^{45-47}$ Specifically, researchers have defined listening both as a pragmatic strategy to reduce medical errors, and a social strategy to foster interpersonal connections. ${ }^{46}$ The pragmatic as well as social dimensions during clinical encounters should therefore be considered in efforts to better align with this conceptual meaning of patient safety.

\section{Study Limitations}

Most patients in the focus groups identified as white; thus, our findings may not be fully indicative of the perspectives among the primary care patient population. In addition, we conducted this study in the context of level 3 PCMHs, which was the highest level of recognition in the NCQA's PCMH model during the study period. The transferability of the findings to other primary care practices that are not level 3 PCMHs, or non-PCMHs, may therefore be limited. However, by targeting highperformance primary care practices like level 3
PCMHs, this study sought to examine a more comprehensive range of conceptual meanings of patient safety in primary care that may not have been fully considered in other primary care practices.

\section{Conclusions}

Conceptual meanings of patient safety in primary care exhibit a high degree of agreement between frontline clinicians, administrators and staff, and patients. However, conceptualizing patient safety in the form of work functions better reflects their experiences than domain-based conceptualizations that are favored by experts. In addition, informational security is also perceived to be an element of patient safety in primary care. This differential approach in conceptualization should be considered in future measurements and interventions to improve overall patient safety in primary care.

The authors gratefully acknowledge the clinicians, administrators, staff, and patients who participated in this study.

To see this article online, please go to: http://jabfm.org/content/ 33/5/754.full.

\section{References}

1. Shojania KG, Dixon-Woods M. Estimating deaths due to medical error: the ongoing controversy and why it matters. BMJ Qual Saf 2016;2016-006144.

2. Wu AW. Medical error: the second victim. The doctor who makes the mistake needs help too. BMJ 2000;320:726-7.

3. Institute of Medicine. To err is human: building a safer health system. Washington (DC): National Academies Press; 2000.

4. Shekelle PG, Sarkar U, Shojania K, et al. AHRQ comparative effectiveness technical briefs. In: Patient safety in ambulatory settings. Rockville (MD): Agency for Healthcare Research and Quality (US); 2016.

5. National Center for Health Statistics. National health interview survey, 2015. Atlanta (GA): Centers for Disease Control and Prevention; 2015.

6. National Center for Health Statistics. National ambulatory medical care survey, 2015. Atlanta (GA): Centers for Disease Control and Prevention; 2015.

7. Montano MF, Mehdi H, Nash DB. Annotated bibliography: understanding ambulatory care practices in the context of patient safety and quality improvement. Am J Med Qual 2016;31:29s-43s.

8. Webster JS, King HB, Toomey LM, et al. Understanding quality and safety problems in the 
ambulatory environment: seeking improvement with promising teamwork tools and strategies. Rockville (MD): Agency for Healthcare Research and Quality (US); 2008.

9. Petterson SM, Liaw WR, Tran C, Bazemore AW. Estimating the residency expansion required to avoid projected primary care physician shortages by 2035. Ann Fam Med 2015;13:107-14.

10. Dall TM, Gallo PD, Chakrabarti R, West T, Semilla AP, Storm MV. An aging population and growing disease burden will require a large and specialized health care workforce by 2025 . Health Aff (Millwood) 2013;32:2013-20.

11. Bates DW, Singh H. Two decades since to err is human: an assessment of progress and emerging priorities in patient safety. Health Aff (Millwood) 2018;37:1736-43.

12. Charles R, Vallee J, Tissot C, Lucht F, BotelhoNevers E. Vaccination errors in general practice: creation of a preventive checklist based on a multimodal analysis of declared errors. Fam Pract 2016;33:432-8.

13. Koper D, Kamenski G, Flamm M, Bohmdorfer B, Sonnichsen A. Frequency of medication errors in primary care patients with polypharmacy. Fam Pract 2013;30:313-9.

14. Hoffmann B, Beyer M, Rohe J, Gensichen J, Gerlach FM. "Every error counts": a web-based incident reporting and learning system for general practice. Qual Saf Health Care 2008;17:307-12.

15. Bondevik GT, Hofoss D, Hansen EH, Deilkas EC. Patient safety culture in Norwegian primary care: a study in out-of-hours casualty clinics and GP practices. Scand J Prim Health Care 2014;32:132-8.

16. Lawati MHA, Dennis S, Short SD, Abdulhadi NN. Patient safety and safety culture in primary health care: a systematic review. BMC Fam Pract 2018;19:104.

17. Baker DW. The meaning and the measure of health literacy. J Gen Intern Med 2006;21:878-83.

18. Thompson AG. The meaning of patient involvement and participation in health care consultations: a taxonomy. Soc Sci Med 2007;64:1297-310.

19. Kodner DL, Spreeuwenberg C. Integrated care: meaning, logic, applications, and implications-a discussion paper. Int J Integr Care 2002;2:e12.

20. Donnellon A, Gray B, Bougon MG. Communication, meaning, and organized action. Administrative Science Quarterly 1986;31:43-55.

21. Weick KE. The social psychology of organizing, 2nd ed. New York: McGraw-Hill; 1979.

22. Weick KE. Sensemaking in Organizations. Thousand Oaks, CA: SAGE; 1995.

23. Daker-White G, Hays R, McSharry J, et al. Blame the patient, blame the doctor or blame the system? A meta-synthesis of qualitative studies of patient safety in primary care. PLoS One 2015;10:e0128329.

24. Gaal S, Van Laarhoven E, Wolters R, Wetzels R, Verstappen $W$, Wensing $M$. Patient safety in primary care has many aspects: an interview study in primary care doctors and nurses. J Eval Clin Pract 2010;16:no-643.

25. Ricci-Cabello I, Pons-Vigués M, Berenguera A, Pujol-Ribera E, Slight SP, Valderas JM. Patients' perceptions and experiences of patient safety in primary care in England. Fam Prev 2016;33:535-42.

26. National Committee for Quality Assurance. PatientCentered Medical Home (PCMH) Recognition. Available from: http://www.ncqa.org/programs/ recognition/practices/patient-centered-medicalhome-pcmh. Published 2018. Accessed June 25, 2019.

27. National Committee for Quality Assurance. Methodology. NCQA Report Cards Web site. Available from: https://reportcards.ncqa.org/\#/ methodology. Published 2018. Accessed April 4, 2020.

28. Agency for Healthcare Research and Quality. Defining the PCMH. Available from: https://www. pcmh.ahrq.gov/page/defining-pcmh . Published 2004. Accessed June 25, 2019.

29. Britten N. Qualitative research: qualitative interviews in medical research. BMJ 1995;311:251-3.

30. Braun V, Clarke V. Using thematic analysis in psychology. Qual Res 2006;3:77-101.

31. MacQueen K, Mclellan-Lemal E, Bartholow K, Milstein B. Team-based codebook development: structure, process, and agreement. In: Guest G, MacQueen K, eds. Handbook for team-based qualitative research. Plymouth, United Kingdom: AltaMira Press; 2008. P. 119-35.

32. Barbour RS. Checklists for improving rigour in qualitative research: a case of the tail wagging the dog? BMJ 2001;322:1115-7.

33. Armstrong D, Gosling A, Weinman J, Marteau T. The place of inter-rater reliability in qualitative research: an empirical study. Sociology 1997;31:597606.

34. Farmer T, Robinson K, Elliott SJ, Eyles J. Developing and implementing a triangulation protocol for qualitative health research. Qual Health Res 2006;16:377-94.

35. Vindrola-Padros C, Johnson G. The narrated, nonnarrated, and the disnarrated: conceptual tools for analyzing narratives in health services research. Qual Health Res 2014;24:1603-11.

36. MAXQDA [computer program]. Berlin, Germany: VERBI Software2017; 2018.

37. Miles MB, Huberman AM, Saldaña J. Fundamentals of qualitative data analysis. In: Qualitative data analysis: a methods sourcebook, 3rd ed. USA: Sage Publications, Inc.; 2014;95-9.

38. U.S. Department of Health and Human Services. Summary of the HIPAA privacy rule. Washington DC, U.S. Department of Health and Human Services; 2003. 
39. Vincent CA, Coulter A. Patient safety: what about the patient?. Qual Saf Health Care 2002;11:76-80.

40. Shekelle PG, Pronovost PJ, Wachter RM, et al. Advancing the science of patient safety. Ann Intern Med 2011;154:693-6.

41. Institute of Medicine Committee on Quality of Health Care in America. Crossing the quality chasm: a new health system for the 21 st century. Washington (DC): National Academy of Sciences; 2001.

42. Hatoun J, Chan JA, Yaksic E, et al. A systematic review of patient safety measures in adult primary care. Am J Med Qual 2017;32:237-45.

43. The Office of the National Coordinator for Health Information Technology. SAFER guides. Available from: https://www.healthit.gov/topic/safety/saferguides. Published 2018. Accessed June 17, 2019.

44. Chinn D. Critical health literacy: a review and critical analysis. Soc Sci Med 2011;73:60-7.

45. Levinson W, Lesser CS, Epstein RM. Developing physician communication skills for patient-centered care. Health Aff (Millwood) 2010;29:1310-8.

46. Wanzer MB, Booth-Butterfield M, Gruber K. Perceptions of health care providers' communication: relationships between patient-centered communication and satisfaction. Health Commun 2004;16:363-83.

47. King A, Hoppe RB. "Best practice" for patient-centered communication: a narrative review. J Grad Med Educ 2013;5:385-93. 
Appendix. Themes and Illustrative Quotes from Clinicians, Administrators, Staff, and Patients on Conceptual Meanings of Patient Safety in Primary Care

Subtheme (Level of

Main Theme (Level of Agreement $\quad$ Agreement between

between Personnel and Patients) Personnel and Patients)

Not causing harm (agreement)

Viewing the patient as a whole (agreement)

Providing appropriate and timely care (agreement)
Social determinants of health (nonnarrated by patients)

Care coordination (partial agreement)
Illustrative Quotes

"I take that Hippocratic Oath of "Do no harm" very seriously. Every kind of prescription I give, every decision I'm going to make, I always think, am I doing more harm than good, so that's sort of my mantra." physician, ID 55, site 6

"They [the practice] always keep up with your medicine.

That's just very important to me. Especially being diabetic. Because some of those medicines just will not, they just don't agree with me. And it's scary when your blood sugar drops and you're just in a pickle." - patient C, site 9

"Patient safety to me, runs a gamut of a whole spectrum of things. It begins in the entire realm of medical care starting in regards to the patient at their home and evaluating that through the entire continuum of medical care, whether it's here at the office, our urgent care centers, our hospital, or any other medical facility. And then, try to evaluate the patient in regards to where are those risks? To the patient's wellbeing? To their health? To their chronic medical illnesses, etcetera. It exists in multiple different areas of the patient's life." -physician, ID 38, site 4

"I think what I've found is that my doctor looks at all of me... [Patient] A has high blood pressure, oh she's anxious. No. Looking at the whole big picture, what's going on in life? What has made you anxious? So not just pinpointing oh here's a medication for that. . looking at all of me and I like that. I like that feeling." -patient A, site 1

"Social determinants when they [patients] come in, thinking about those types of things, like, do they have insurance? Do they have a job? Do they have ways of paying for medications? Especially chronic diseases. . .because sometimes they'll come in and they don't have the money to pay for medications and that's not safe for them if they can't take their medicine, so we try to help them as best as we can." -practice manager, ID 82, site 9

"First, do no harm. But, in a broader sense, it is the right care for the right patient at the right time. So, expounding on that, it means understanding the patient, their situation, in a timely way, you know, which would involve recognition of issues in a timely way, and then direction into the right treatment pathways." -physician, ID 65, site 7

"When you come here and see a doctor or PA [Physician Assistant] for medical advice and care, it's care that's going to take care of you. And in fact, what you're coming in with is going to be dealt with. If they can't cure it, at least they can tell you what it is and maybe start you on a program to handle that. It doesn't get worse and they don't misdiagnose. I'd say those are the two things that would make me wonder if it's safe." -patient A, site 3

"If their safety is they need a CAT [computerized axial tomography] scan, we have to make sure it's going to get done and get it done in a timely manner and make sure that if anything has to happen after that, if they need to see a surgeon or whatever, that's safety because we're seeing the patient from beginning to end and make sure that, again, that loop is completed. . .And the other thing, too, is following through with referrals, appointments to a specialist and tests, and things that the doctors order at the time of the visit. So, we do a loop with ordering it, scheduling it, following through, and we get the report." -administrator, ID 39, site 4

"You rely more on your primary care physician to direct 
Shared decision-making (agreement)
Ensuring physical safety and informational security of the practice environment (agreement) you to the specialties and I think hopefully you have trust in them enough that they are directing you to the proper specialty because I think that concerns me as far as safety because I don't know who's out there, so I have to rely on her to tell me now okay, we're going to set up an appointment for you with Dr. so-and-so to look at whatever. So, how are we to know with the professional we're now going to. We're leaving our primary care physician, who we liked very much, is directing us to the right specialty." -patient $\mathrm{E}$, site 4

"[Patient safety is] care where we get the best outcome for the patient. . .get the patient involved. . I've always had my philosophy that the patient needs to be involved. And my role is a consultant and teaching the patient as much as possible as to what's going on. Patient safety is that the patient is aware of it, knows why we're doing it is on board with doing whatever the intervention is and complies with it and hopefully gets the good results." physician, ID 17 , site 2

"Ensuring that the patient understands what's going on, why you're doing it, what the risks are, what the complications may be, and involving the patient in involving the patient in their own treatment so that they understand the importance of what has to be done and why they should do it and to me, that's safety. That's important safe medical care." -patient C, site 2

"So safe medical care means to me that. . .when the patient comes in, they can safely get to the chair, they can safely room, you know, go to the bathroom by themselves. . their stability and their balance and everything are intact where they're not falling. Very simple. Well, there are bars in the bathroom for the patient to make sure that they can sit properly if they are handicapped and there's no steps. There's a ramp and there's the doors that open automatically, which we use. Probably what I would assess here at the practice being patient safety is that we have the bars and we have the equipment." -medical assistant, ID 58, site 6

"I'm ambulatory, but I do walk with a cane. So, to me it starts before I get into the office. Is there snow removal, ice, handicap parking, can I even make it to the door. . I've been to specialist's office in the winter time and had to just say no. I'm not even going to attempt it. Snow, ice, steps, no handicap [parking]." -patient C, site 6

"Patients feeling like their information is safe and that they feel like their HIPAA [Health Insurance Portability and Accountability Act] is not being violated. I think sometimes the office is a bit like, you're seeing other patients, your information is kind of there. .. think that that's an important part of patient safety is making sure their health information is safe." -physician, ID 87 , site 10

"In light of everything that's going on in the world today with identity theft, I'm concerned with measures that are taken, that our records will be secure. I'm also concerned that when new applicants come to the clinic to work at the clinic, from doctors all the way down to the person answering the phone, that secure background checks are made, that these people are also reliable and not people that would take our information and somehow use it." patient $B$, site 4 
Main Theme (Level of Agreement between Personnel and Patients)

Communicating attentively (nonnarrated by personnel)
Subtheme (Level of

Agreement between

Personnel and Patients)
Illustrative Quotes

"We all have different little medical concerns and you can just ask him [the physician] a question and you get an answer so quickly. . . so I feel safe in the fact that he's actually listening to me and actually hearing everything I have to say. . .you think you have this and it's like 'no, you don't have that you have this,' and it's so much simpler. You're not so worried because we do go on the Internet and we do read things and you're like oh my God, I have this and I'm going to die. So, I feel safe that he listens to me and that I'm going to get the right results." -patient $\mathrm{B}$, site 5 